\title{
Four Years' Experience of Application of Low-Cost Sensors in Belgrade in the Framework of the CITI-SENSE Project
}

\author{
Milena Jovašević-Stojanović ${ }^{1}$, Dušan Topalović ${ }^{2,1}$, Miloš Davidović ${ }^{1}$ Ivan Lazovic ${ }^{1}$, Marija Živković ${ }^{1}$, \\ Zoran Ristovski ${ }^{3}$, Alena Bartonova ${ }^{4}$ \\ ${ }^{1}$ Vinča Institute of Nuclear Sciences, University of Belgrade, P. O. Box 522, 11001, Serbia \\ ${ }^{2}$ School of Electrical Engineering, University of Belgrade, P. O. Box 35-54, 11120 \\ ${ }^{3}$ International Laboratory for Air Quality and Health, Queensland University of Technology, Australia \\ ${ }^{4}$ Norwegian Institute for Air Research, P. O. Box 100, 2027, Norway \\ mjovst@vin.bg.ac.rs
}

\begin{abstract}
This paper presents the results of 4 year application of low-cost sensors in Belgrade within the CITISENSE project activities. It is explained how the "citizens' observatories" are the basic concept of CITI-SENSE project which empower citizens to contribute and participate in the process of making political decisions concerning the environment. The basic elements of the project, which are based on tools and devices for distributed air pollution monitoring in urban areas, are described. Platforms with low-cost sensors that have been developed within the project are presented. Comparative statistical analysis of their evaluation was performed by using measurements from the reference monitoring station which is operated by the Serbian Environmental Protection Agency (SEPA).
\end{abstract}

Key words: Air-pollution, CITI-SENSE, low-cost, platforms

\section{Introduction}

Air pollution is not constant in level and composition, varies through space and time and stems from both anthropogenic and natural emissions. Premature deaths, attributable to air pollution, happen mostly due to heart disease and stroke, followed by lung diseases and cancer [1]. In addition, air pollution is associated with increase in incidence of numerous additional diseases. IACR designated outdoor air pollution as a Group 1 carcinogenic substance and RPM mixture was evaluated separately and also classified in the Group 1 [2].

WHO established air quality guideline in 2006 [3]. However, ten years after, air pollution is still the single largest environmental health risk in Europe [4]. It is estimated that level of regulated air pollutants in most European cities are far above the air quality guidelines values [4]. Serbian Environmental Protection Agency (SEPA) reported that more than $30 \%$ of citizens of Serbia were exposed to air that is considered not healthy in 2014. Recently, a new WHO air quality model confirmed that $92 \%$ of the world's population lives in places where air quality levels exceed WHO limits.

As such, citizens are at risk to be exposed to potentially harmful levels of air pollutants. More and more cities provide timely air quality information to the public through printed and electronic media including web pages and mobile apps.

The information on the $A Q$ and related hazards is currently mostly generic, and seldom personally relevant. It would be necessary to offer information to a person about $A Q$ level in microenvironment, especially on the routes they frequently use, and then describe in detail what does this information means for her/him health wise. It is of ultimate importance for citizens to recognize the problems and to have option to change their behaviour which is directly related to their contribution and their exposure to air pollution.

\section{The CITI-SENSE project concept}

CITI-SENSE project (2012-2016) developed "citizens' observatories" in the aim of empowering citizens to contribute and participate in environmental governance. These observatories enable them to support and influence community and societal priorities and associated decision making.

The concept of CITI-SENSE rested on three pillars:

- technological platforms for distributed monitoring 
- information and communication technologies

- societal involvement

Three multi-center case studies focused on a range of services related to environmental issues of societal concern, and were performed in 8 European cities:

1. Combined environmental exposure and health associated with ambient outdoor and indoor air quality

2. Noise and development of public spaces

3. Indoor air at schools.

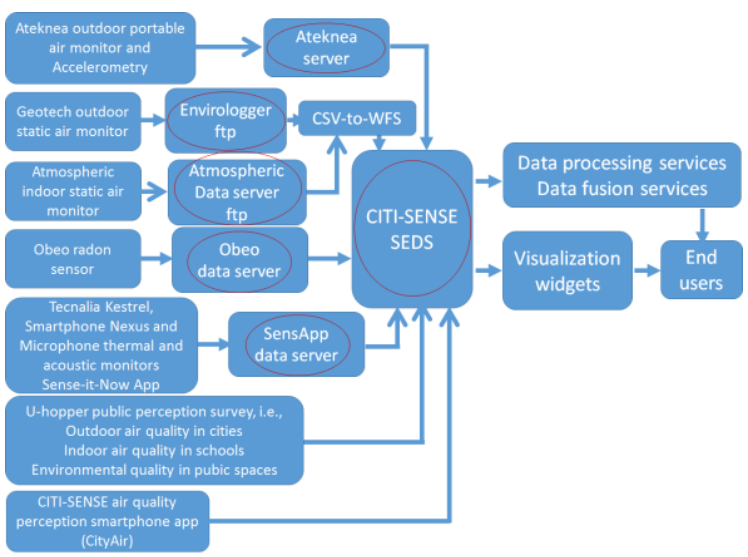

Fig. 1. CITI-SENSE platform data flow.

Figure 1 shows a CITI-SENSE platform data flow. Within CITI-SENSE, there were nine pilot cities, including Belgrade, that employed one or more end user 'products' developed within the project. These products were built on top of various support services, such as sensor platforms, GIS, WMS, or mathematical modeling that have potential to provide seamless functioning of products.

\section{Technological platforms for distributed monitoring}

Within the CITI-SENSE project activities two different approaches for collecting information about air pollution were used:

1. Direct - by using Little Environmental Observatory (LEO) for direct personal exposure assessment (manufactured by Ateknea) and City Air mobile application for building a map of subjective perception of air quality in cities.

2. Indirect - by using a network of static sensors distributed over the city. The sensor data are combined with statistical models using data fusion techniques, to provide air quality maps for the city, which benefit from both model and the measurements. Within CITI-SENSE project three different platforms were used for measurements: 1) EB700
DNET (outdoor), 2) Geotech AQMESH (outdoor) and 3) Alphasense Atmospheric platforms (indoor) (Figure 6).

\section{Direct approach}

LEO (Figure 2) is a portable sensor package $(80 \times 96 \times 44 \mathrm{~mm})$ in which a total of 3 electrochemical Alphasense sensors are integrated, namely sensors for $\mathrm{NO}_{2}, \mathrm{NO}$ and $\mathrm{O}_{3}$. Also, this portable package contains sensors for temperature and relative humidity. LEO is used via smartphone app "Expo App" (Figure 3) that was developed for Android mobile phones. Using bluetooth connection data from the sensors are sent to the phone, and later uploaded over the internet connection to the appropriate server for storage and visualization (Figure 4).

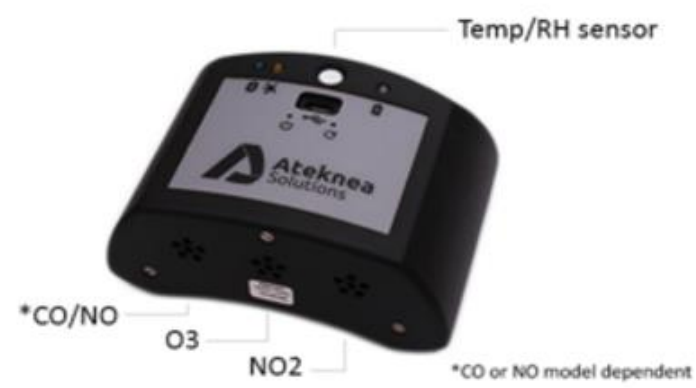

Fig. 2. LEO personal device.
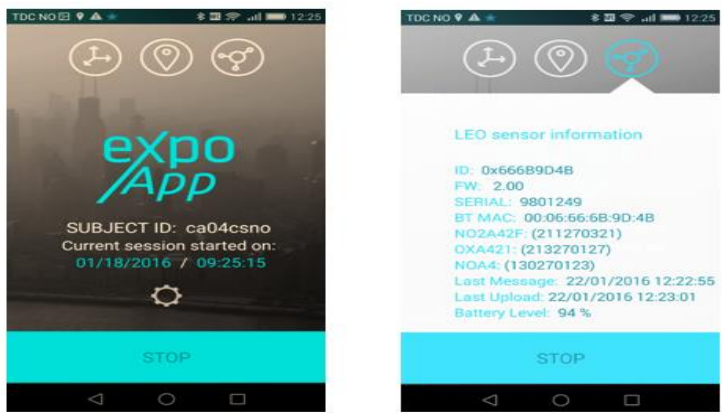

Fig. 3. Mobile application for LEO personal deviceExpoApp.

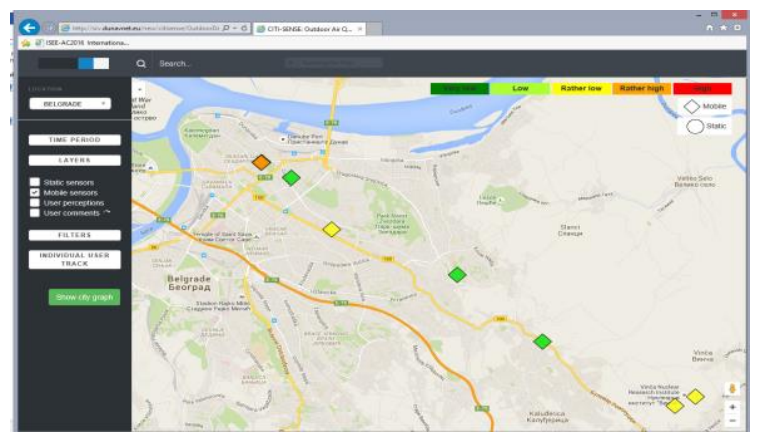

Fig. 4. Looking up LEO data.

During CITI-SENSE, in addition to LEO "Expo App", CityAir smartphone application was also developed. Anyone with smartphone can use this app to express their perception of the 
outdoor air quality at their location, and indicate sources of reduced air quality. Example of perception map, as created by app users in Belgrade is shown on Figure 5.

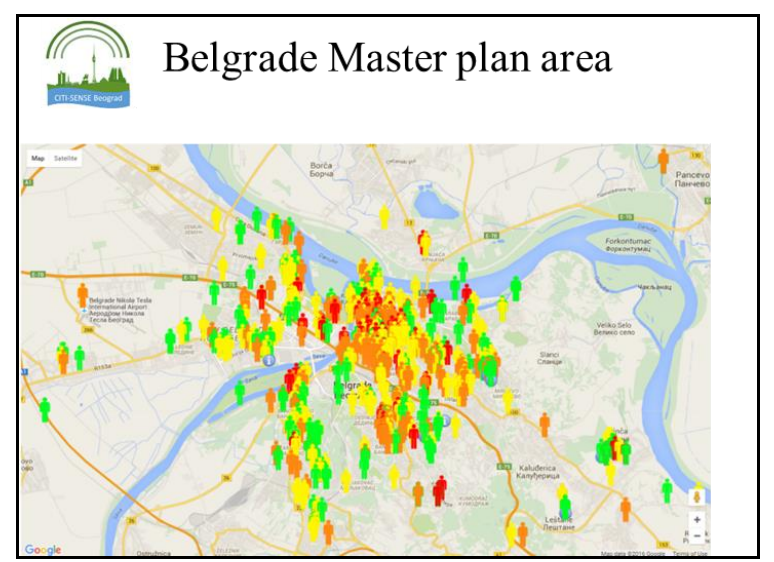

Fig. 5. Perception map created using CityAir app.

Green color represents city locations with good air quality index, while other colors represent locations were air quality is lower, according to subjective opinion of app users.

\section{Indirect approach}

In recent years small portable systems implementing low-cost sensors for detection of particle concentrations are increasingly being used to support standard measuring stations, since they can typically provide higher spatial and temporal resolution of measurements. Based on experience from studies that have used these low-cost sensors for air pollution monitoring, it was concluded that when low-cost sensors are used in real-time measurements it is also necessary to perform an evaluation of their characteristics. In the next section, statistical analysis of the performance of low cost sensors from three different platforms used within CITI-SENSE project activities is presented.

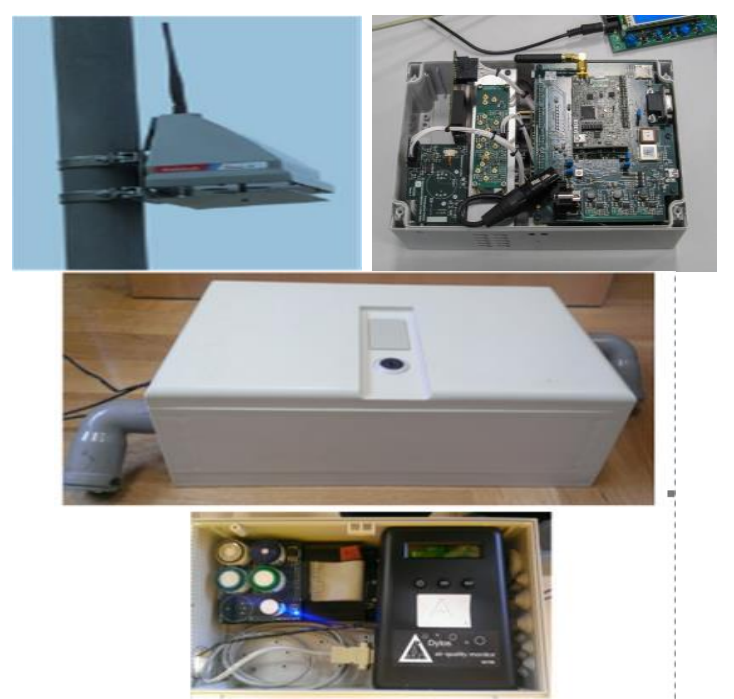

EB700, AQMESH and Atmospheric units are using the Alphasense [5] electrochemical B4 gas sensors for $\mathrm{CO}, \mathrm{NO}, \mathrm{NO}_{2}$ and $\mathrm{O}_{3}$. NDIR $\mathrm{CO}_{2}$ sensor was integrated in DNET and Atmospheric, but not in AQMESH pods. DNET had integrated Dylos 1700 particle monitor for $\mathrm{PM}_{2.5}$ and $\mathrm{PM}_{10}$. Dylos 1700 is a Laser Particle Counter with two size ranges $(0.5 \mu \mathrm{m}<d$ $<2.5 \mu \mathrm{m})$ and $(2.5 \mu \mathrm{m}<d<10 \mu \mathrm{m})$. AQMESH and Atmospheric had Alphasense OPC N1 particle sensors for $\mathrm{PM}_{2.5}$ and $\mathrm{PM}_{10}$ fractions. All platforms had integrated sensors for temperature, pressure and humidity.

\section{Results and discussion}

We compared results from low-cost sensors and results from referent measurement station. The simplest way of comparison was to establish Pearson correlation between different sensors and reference monitors. Experiments were conducted on the two reference monitoring stations: (1) Belgrade Zeleno Brdo and (2) Belgrade Stari Grad. Belgrade Zeleno Brdo (20 $31^{\prime} 18^{\prime \prime} \mathrm{E}, 44^{\circ} 47^{\prime} 11^{\prime \prime} \mathrm{N}$ ) could be classified as a background station in suburban area, located at an altitude of $243 \mathrm{~m}$. Belgrade Stari Grad (20 $\left.27^{\prime} 32^{\prime \prime} \mathrm{E}, 44^{\circ} 49^{\prime} 16^{\prime \prime} \mathrm{N}\right)$ is the background station in the urban area of the city, at an altitude of $97 \mathrm{~m}$. Ranges of Pearson correlation coefficient between 3 types of platforms and 2 reference stations are presented in Table 1 and Table 2, respectively.

Table 1. Pearson correlation from station Zeleno Brdo

\begin{tabular}{|c|c|c|c|}
\hline \multicolumn{4}{|c|}{ Pearson correlation coefficient within unit type EB700, AQMesh and Model 510} \\
\hline \multirow[b]{2}{*}{ Sensor } & \multicolumn{3}{|c|}{ Unit type (number of units of each type depolyed in Belgrade) } \\
\hline & $\begin{array}{c}\text { EB700, } \\
\text { Dunavnet } \\
(n=10)\end{array}$ & $\begin{array}{c}\text { AQmesh, } \\
\text { Environmental } \\
\text { Instruments }(n=25)\end{array}$ & $\begin{array}{c}\text { Model } 510 \\
\text { Atmospheric } \\
(n=12)\end{array}$ \\
\hline $\mathrm{NO}_{2}$ & $0.10-0.92$ & $0.40-0.70$ & $0.50-0.98$ \\
\hline $\mathrm{NO}$ & $0.20-0.97$ & $0.15-0.45$ & n.a. \\
\hline $\mathrm{CO}$ & $0.50-0.98$ & $0.50-0.90$ & $0.96-0.98$ \\
\hline $\mathrm{CO}_{2}$ & $0.64-0.96$ & n.a. & $0.94-0.98$ \\
\hline $\mathrm{O}_{3}$ & $0.40-0.90$ & $0.01-0.60$ & $0.69-0.91$ \\
\hline $\mathrm{PM}_{2.5}$ & $0.70-0.96$ & $0.60-0.90$ & $0.52-0.85$ \\
\hline $\mathrm{PM}_{10}$ & $0.60-0.88$ & $0.50-0.80$ & $0.50-0.70$ \\
\hline Meteo $(\mathrm{T}, \mathrm{RH}, \mathrm{P})$ & $>0.90$ & $>0.90$ & $>0.90$ \\
\hline
\end{tabular}

Table 2. Pearson correlation from station Stari Grad

\begin{tabular}{|c|c|c|c|}
\hline \multicolumn{4}{|c|}{$\begin{array}{l}\text { Pearson correlation coefficient between EB700, AQMesh, Model } 510 \text { collocated at } \\
\text { and reference station Stari Grad }\end{array}$} \\
\hline \multirow[b]{2}{*}{ Sensor } & \multicolumn{3}{|c|}{ Unit type (number of units of each type deployed in Belgrade) } \\
\hline & $\begin{array}{c}\text { EB700, } \\
\text { Dunavnet } \\
(n=10)\end{array}$ & $\begin{array}{c}\text { AQmesh, } \\
\text { Environmental } \\
\text { Instruments }(n=25)\end{array}$ & $\begin{array}{c}\text { Model } 510 \\
\text { Atmospheric } \\
(n=12)\end{array}$ \\
\hline $\mathrm{NO}_{2}$ & $-0.19-(-0.74)$ & $-0.002-0.51$ & $0.001-0.20$ \\
\hline NO & $-0.01-0.27$ & $0.003-0.26$ & - \\
\hline $\mathrm{CO}$ & $0.26-0.97$ & $0.12-0.82$ & $0.10-0.52$ \\
\hline $\mathrm{CO}_{2}$ & $-0.41-(-0.76)$ & - & - \\
\hline $\mathrm{O}_{3}$ & $-0.04-0.52$ & $0.18-0.85$ & $0.07-0.33$ \\
\hline $\mathrm{PM}_{2.5}$ & $0.55-0.89$ & $0.06-0.60$ & $0.03-0.34$ \\
\hline $\mathrm{PM}_{10}$ & $0.44-0.87$ & $-0.02-0.50$ & $0.05-0.23$ \\
\hline Meteo $(\mathrm{T}, \mathrm{RH}, \mathrm{P})$ & $0.91-0.99$ & $0.15-0.97$ & - \\
\hline
\end{tabular}

Fig. 6. CITI-SENSE static monitoring platforms. 
EB700 During campaigns, ten EB700 DNET pods were used. Almost all $\mathrm{CO}$ sensors showed excellent R-values, over 0.90 during both campaigns. Results were slightly better in the first campaign. Pearson correlation for $\mathrm{CO}$ was in the range $0.50-0.98$ for first campaign and range $0.26-0.97$ in second campaign.

$\mathrm{CO}_{2}$ low cost sensors showed better results during first campaign. R-values were in the range 0.64-0.96. However, during the second campaign we obtained lower results in the absolute range 0.41-0.76.

For $\mathrm{O}_{3}$, Pearson correlation coefficients were generally lower for all sensors and they varied during all campaigns in the range 0.04-0.90.

Good agreement was established between the DYLOS monitors and GRIM devices for particulate matter. With the exception of one DYLOS monitor, that had a problem with the ventilator during the first campaign, all other low-cost devices correlated very well with the reference instrument having R-value for both PM fractions in the range $0.44-0.96$.

There is a big difference in correlation for NO during first and last campaign. During first campaign for NO $\mathrm{R}$ was in the range 0.20-0.97 and in second range became smaller 0.01-0.27. Intra sensors variance was highest for $\mathrm{NO}_{2}$, in the range 0.352-0.737, after one sensor that showed much lower correlation with the reference device was excluded from analysis. $R$ values for $\mathrm{NO}_{2}$ were $0.10-0.92$ in the first and 0.19-0.74 in the second campaign.

AQMESH According to results from comparison of same sensors from 25 platforms it can be concluded that sensors have a high degree of correlation. $\mathrm{NO}_{2}$ sensors had worst correlation. Based on a comparison with the reference measurements we found that AQMesh platforms obtained lower results in comparison with DNET platforms, especially in the first campaign. Results from the first campaign were better when compared to second campaign, which can be explained by sensors aging. In the first campaign $\mathrm{CO}$ and OPC N-1 sensors shown the best performances and in second campaign we obtained surprisingly good results for $\mathrm{O}_{3}$ sensors.

ATMOSPHERIC During campaigns in Serbia we used 12 Atmospheric platforms. It was found that for $\mathrm{CO}, 12$ platforms showed a very high correlation among themselves, but we found low correlation with referent monitor. For $\mathrm{NO}_{2}$ we obtained slightly lower Pearson correlation within $\mathrm{NO}_{2}$ sensors from different platforms but it was still $>0.7$. On the other hand, here we had a very low correlation with reference monitor. For $\mathrm{O}_{3}$ we obtained slightly better correlation in comparison to $\mathrm{NO}_{2}$. Finally, some of the particle sensors did not function, as they had constant response values. Because of that, it was not possible to conduct evaluation procedure, even after firmware update, as suggested by manufacturer. Rest of the particles sensors showed unsatisfactory trend regarding correlation with reference measurements, since in second campaign $R$ values were in range 0.03-0.34. One optical particle monitor was also tested independently from the platform. In laboratory conditions, we compared measurements from OPC Alphasense and Dylos 1700 with referent measurements. It was found that numerical values from OPC Alphasense are in better agreement with reference measurements compared to Dylos 1700 device.

\section{Conclusion}

For larger scale deployment of technological platforms which utilize low-cost sensors for purposes of distributed monitoring, several conditions need to be satisfied:

- integrated sensors for gases and particulate matter need to have uniform response

- efficient calibration procedures need to be established with minimal increase in cost of platforms for distributed monitoring.

\section{Acknowledgements}

The low-cost sensors and IC technologies described here evolved through the work undertaken by the CITI-SENSE Consortium. CITI-SENSE is a collaborative project partly funded by the EU FP7-ENV-2012 under grant agreement no 308524 in period 2012-2016.

\section{References}

[1] WHO, "Burden of disease from Ambient Air Pollution for 2012 - Summary of results" World Health Organization 2014, http://www.who.int/phe/health topics/outdoorair/d atabases/AAP_BoD_results_March2014.pdf, accessed February 2016.

[2] IARC press release https://www.iarc.fr/en/mediacentre/iarcnews/pdf/pr221_E.pdf, accessed February 2016.

[3] WHO, 'Air Quality Guidelines. Global update 2005. Particulate matter, ozone, nitrogen dioxide and sulfur dioxide". WHO Regional Office for Europe, Copenhagen. 2006

[4] EEA, Air quality in Europe - 2015 report. Copenhagen, EEA Report No 5/2015

[5] http://www.alphasense.com/ 